\title{
Intraoperative neuromonitoring of the RLNs during TOETVA procedures
}

\author{
Varlık Erol $^{1}$, Gianlorenzo Dionigi ${ }^{2}$, Marcin Barczyński $^{3}$, Daqi Zhang ${ }^{4}$, Özer Makay ${ }^{5}$ \\ ${ }^{1}$ Department of General Surgery, Zubeyde Hanim Practice and Research Center, Baskent University, Izmir, Turkey; ${ }^{2}$ Division for Endocrine \\ and Minimally Invasive Surgery, Department of Human Pathology in Adulthood and Childhood "G. Barresi", University Hospital G. Martino, \\ University of Messina, Messina, Italy; ${ }^{3}$ Department of Endocrine Surgery, Third Chair of General Surgery, Jagiellonian University Medical College, \\ Kraków, Poland; ${ }^{4}$ Division of Thyroid Surgery, China-Japan Union Hospital Of Jilin University, Jilin Provincial Key Laboratory of Surgical \\ Translational Medicine, Jilin Provincial Precision Medicine Laboratory of Molecular Biology and Translational Medicine on Differentiated Thyroid \\ Carcinoma, Changchun 130000, China; ${ }^{5}$ Department of General Surgery, School of Medicine, Ege University, Bornova, Izmir, Turkey \\ Contributions: (I) Conception and design: Ö Makay, G Dionigi; (II) Administrative support: G Dionigi, M Barczyński; (III) Provision of study \\ materials or patients: V Erol, G Dionigi, M Barczyński, Ö Makay; (IV) Collection and assembly of data: V Erol, G Dionigi, M Barczyński, Ö Makay; \\ (V) Data analysis and interpretation: V Erol, G Dionigi, M Barczyński, Ö Makay; (VI) Manuscript writing: All authors; (VII) Final approval of \\ manuscript: All authors. \\ Correspondence to: Özer Makay. Department of General Surgery, School of Medicine, Ege University, Bornova, Izmir, Turkey. \\ Email: makayozer@yahoo.com.
}

\begin{abstract}
Transoral endoscopic thyroidectomy by vestibular approach (TOETVA) is now being performed in increasing frequency and getting more and more attention. TOETVA is carried out through three incisions in the oral vestibular area. Thyroidectomy is performed endoscopically using conventional laparoscopic instruments, an energy based device and neuromonitoring instruments. Intraoperative neuromonitoring is one of the tools of utmost importance, used for navigation and confirmation of the functional integrity of the recurrent nerve during TOETVA. The aim of this study is to give information about the standards and technique of intraoperative neuromonitoring of the recurrent laryngeal nerves during TOETVA procedures. TOETVA is a safe technique with no visible scarring and hence resulting in an excellent cosmetic effect. We believe that neuromonitoring of the recurrent laryngeal nerves also minimizes the risk of nerve damage and is an essential safety component in this technique.
\end{abstract}

Keywords: Neuromonitoring; surgical technique; transoral endoscopic thyroidectomy by vestibular approach (TOETVA)

Submitted Oct 24, 2019. Accepted for publication Nov 20, 2019.

doi: $10.21037 /$ gs.2019.11.21

View this article at: http://dx.doi.org/10.21037/gs.2019.11.21

\section{Introduction}

Recently, numerous new techniques have been described to get more advanced cosmetic results after thyroidectomy. Natural orifice transluminal endoscopic surgery (NOTES) for thyroidectomy was developed. First endoscopic thyroidectomy described in 1997 (1) and first transoral thyroidectomy was cited as a novel means of procedure to be utilized for minimally invasive thyroid resection by
Witzell et al. (2). Transoral endoscopic thyroidectomy by vestibular approach (TOETVA) is a promising procedure with many advantages such as truly scar free healing, minimally invasive dissection, and accessible approach to both thyroid lobes (3).

In addition to the cosmetic advantages of transoral surgical techniques, the prevention of recurrent laryngeal nerve (RLN) and superior laryngeal nerve (SLN) injury has also been discussed. The first neuromonitoring of the 
RLN during the thyroid surgery with the endotracheal tube attached to the non-invasive surface electrode was performed by Lamade in 1996 (4). Continuous neuromonitoring of the RLN with vagus probe was also developed by Lamade (5). The gold standard method to protect RLN during thyroid and parathyroid surgery is to observe the nerve routinely and monitoring its integrity in the surgical field. Intraoperative neuromonitoring (IONM) is a method based on the visualization of the nerve in addition to the dynamic evaluation of nerve functions during surgery (6-8). The aims of IONM in thyroid surgery are: nerve identification, nerve mapping, support to dissection, nerve injury detection, postoperative prediction of nerve status and functional prediction of nerve status. Monitoring methods that have been applied for approximately 50 years are: glottic pressure monitoring, glottic observation method, endoscopically placed intramuscular vocal cord electrodes, intramuscular electrodes placed through the cricothyroid membrane, laryngeal palpation method and endotracheal tube monitoring with surface electrodes $(9,10)$. Recently, IONM in endoscopic thyroid surgery means monitoring with endotracheal tube with surface electrodes.

Herein, we tried to describe the technique and equipment of IONM during TOETVA, and the value of using IONM during TOETVA.

\section{Standard steps of IONM during TOETVA}

Monitored TOETVA is performed according to standards of equipment set up, induction and maintenance anesthesia, correct tube positioning verification tests, EMG (electromyography) definitions described by the International Neural Monitoring Study Group (INMSG) Guidelines (8). We prefer endotracheal tube-based surface electrodes for monitored TOETVA because of safety and simplicity of this system.

Nerve monitoring descriptions and sequence for IONM in TOETVA:

(I) $\mathrm{V} 1=$ test vagus nerve before identification of RLN.

(II) $\mathrm{R} 1=$ test RLN when it is identified at the tracheoesophageal groove.

(III) $\mathrm{R} 2$ = test RLN after it is completely dissected from Berry's ligament.

(IV) $\mathrm{V} 2=$ test vagus nerve after complete hemostasis.

\section{Induction}

For successful nerve monitoring, since it may be severely affected by muscle relaxants, fentanyl $2 \mu \mathrm{gr} / \mathrm{kg}$-thiopental $5 \mathrm{mg} / \mathrm{kg}$ can be used for anesthesia induction, after that depolarizing (succinylcholine) or non-depolarizing muscle relaxants (rocuronium, atracurium) may be used depending on the choice of anesthetist for intubation, but at a low dose (0.3-0.5 $\mathrm{mg} / \mathrm{kg}$ for rocuronium).

\section{Intubation}

Intubation should be performed nasotracheally or orotracheally with a tube that is integrated and paired with left and right stainless steel electrodes embedded within the endotracheal tube surface. Endotracheal EMG tube electrodes advantages are: availability of tube, safety, noninvasive, easy setup, ease of use and derive larger areas of evoked muscle potentials. The electrodes are connected to the IONM monitor. Tables 1,2 concentrate on the advantages/disadvantages of intubation methods and contraindications for nasotracheal intubation.

\section{Equipment for IONM}

Usually a single-/multi-use, $230 \mathrm{~mm}$ ball tip long monopolar stimulation probe is used for nerve stimulating. Other probes, which can be used for IONM during TOETVA, are: percutaneous probe, flexible wire probe, conventional endoscopic instruments integrated with the IONM wires and a flexible probe (Figure 1). The advantage of endoscopic instruments is that they can allow dissecting and stimulating at the same time. Stimulating probes may be monopolar or bipolar. There is insufficient literature data to comment as to which stimulating electrode type is preferable (Table 3). It is important to use a long stimulating probe to reach the neck from oral cavity, if a percutaneous probe will not be used.

\section{Surgical technique}

TOETVA is made by 3 incisions at the oral vestibular area under general anesthesia and patients are endotracheally intubated with a nerve monitoring tube. The patient is made sure that he/she is in supine position, with the neck being extended during which we prefer a vestibular approach. In an attempt to insert trocars, a $2 \mathrm{~cm}$ incision is applied in the midline of the lower lip nearly $1 \mathrm{~cm}$ above gingivobuccal sulcus. Electrocautery and a surgical clamp are both utilized in order to access the mandibular epiperiosteum. Soon after having an access to submental space and creating a pocket, 
Table 1 Advantages and disadvantages of intubation methods

\begin{tabular}{lll}
\hline & Orotracheal intubation & Nasotracheal intubation \\
\hline Advantages & Easy & No interaction with instruments \\
Quick & Easy to secure \\
Less contamination & Less extubation \\
& Less tube displacement with head positioning & \\
& Better vocal cord contact & \\
Interact with instruments & Needs experience \\
Hard to secure & Displacement with position \\
& Accidental extubation & Difficult troubleshooting \\
& Accidental disconnection & Thinner tube \\
& Inadequate electrode contact \\
\hline
\end{tabular}

Table 2 Contraindications for nasotracheal intubation

\begin{tabular}{ll}
\hline Absolute & Relative \\
\hline Suspected epiglottitis & Large nasal polyps \\
Midfacial instability & Suspected nasal foreign bodies \\
Coagulopathy & Recent nasal surgery \\
Suspected basilar skull fracture & Upper neck hematoma or infection \\
& History of frequent episodes of epistaxis \\
\hline
\end{tabular}
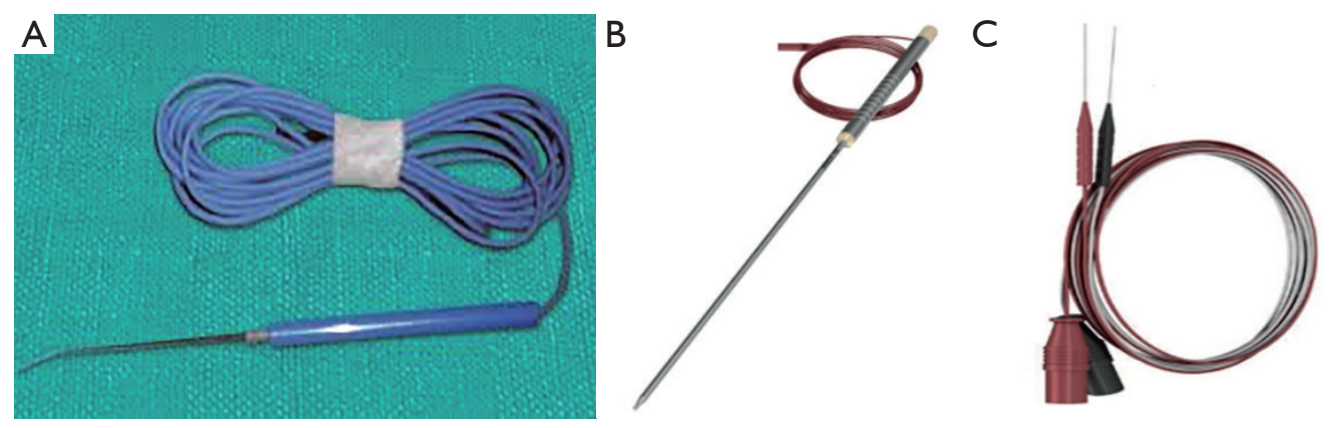

D

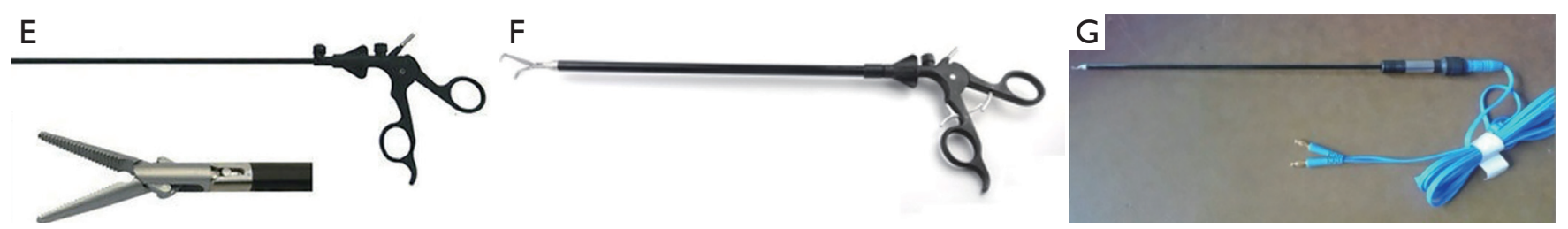

Figure 1 Stimulating probes used for TOETVA. (A) Percutaneous probe, (B) long probe, (C) flexible wire probe, (D) flexible probe, (E) endoscopic instrument probes. TOETVA, transoral endoscopic thyroidectomy by vestibular approach. 
Table 3 Advantages and disadvantages of stimulating probes

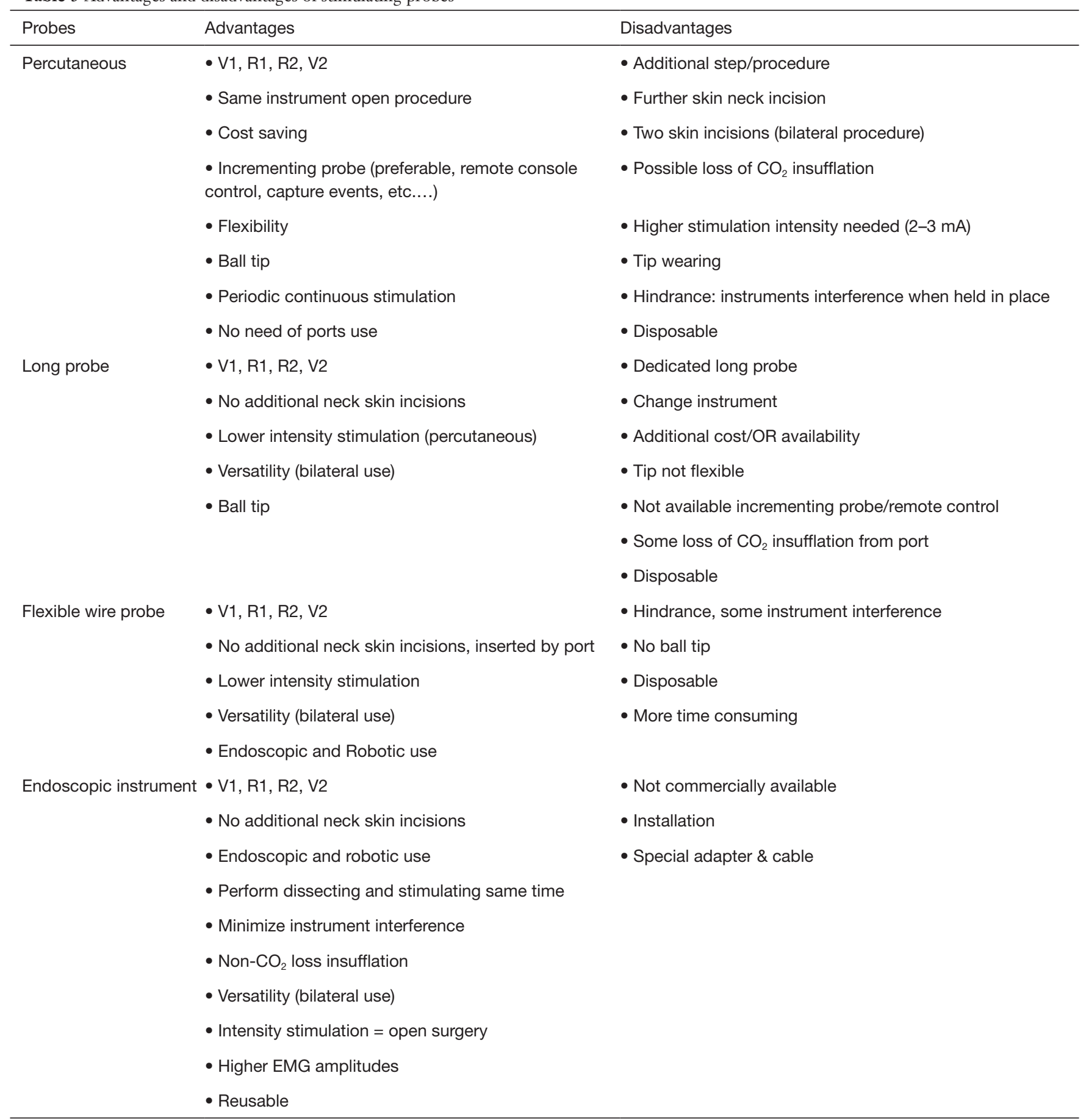

we prefer a blunt-tipped dilator so that a submental and subplatysmal plane can atraumatically be developed in the midline.

Following this, a $10 \mathrm{~mm}$ port is inserted for camera to view accurately and $5 \mathrm{~mm}$ ports are laterally passed through for the effector arms to be better operative. All anatomical structures should be well cared during the course of port placement procedure (11). It is recommended that insufflations tubing be connected to any of these cannulas and also the area of the surgical procedure is made sure 
to be expanded by means of $\mathrm{CO}_{2}$ insufflation at a pressure not reaching $6 \mathrm{mmHg}$. While a 30-degree endoscope is forwarded through the available $12 \mathrm{~mm}$ port, it is recommended that a Maryland dissector and energy-driven device are inserted through other ports.

Platysma is raised from the level of mandible to the level of sternum and then laterally to sternocleidomastoid muscles under endoscopic screening. There is thyroid cartilage located in the upper margin of the flap, while lower margin is the sternal notch and lateral margins are the medial aspect of the sternocleidomastoid muscle. It is recommended that the dissection be proceeded down to the level of the thyroid cartilage notch and also median raphe of the strap be specified and divided in order to expose the thyroid gland. V1 response should be obtained before starting the thyroid tissue dissection. The thyroid is split in the isthmus and the posterior surface of the isthmus is separated from the trachea to the ligament of Berry under craniocaudal view. We first lift the superior pole and following this continue with separating the superior thyroidal vessels with energy device. During the course of lateral dissection, superior parathyroid glands are identified and protected. In this process, RLN is made sure to be identified at the entry point. Then the gland is medially pulled back further, which would enable a capsular dissection. We continue the dissection by dissecting ligament of Berry and the specimen obtained is taken through the camera port.

Difficulties in IONM during TOETVA are:

(I) Limited operating area:

i. Limited port number;

ii. Limited area for IONM probe;

iii. Super positioning of hand instruments;

iv. Impractical access for C-IONM.

(II) Identification of nerve:

i. Cranio-caudal dissection;

ii. Extra retraction for vagus nerve monitoring.

(III) Probe:

i. Access during dissection;

ii. Changing instruments.

(IV) Intubation tubes:

i. Length;

ii. Positioning.

\section{Loss of EMG signals (LOS) during TOETVA}

Although IONM is routinely used for RLN identification, RLN palsy still occurs. Nearly $80 \%$ of the lesions are located at the distal $1 \mathrm{~cm}$ of the course of the RLN. The surgeon may face 2 types of injury: Type 1 (segmental) and Type 2 (diffuse) RLN injuries. With LOS, two issues should be considered: (I) identification of the site of lesion-that is, neural injury point mapping and (II) consideration of optimal contralateral surgery timing (11). The "LOS troubleshooting algorithm" should be applied systematically (12) (Figure 2). Compared to open surgery, it is not possible to check the laryngeal twitch during TOETVA.

\section{Discussion}

Bilateral total thyroidectomy can be successfully performed with TOETVA. TOETVA is a surgical procedure applied with the same technique all over the world. This scarless approach provides equal access to both central necks as opposed to other remote-access approaches. We should monitor and protect bilateral recurrent laryngeal nerves and four parathyroid glands during the course of the surgery. The most common complications in transoral thyroidectomy are hypoparathyroidism, RLN injury and mental nerve palsy. Other complications are skin ecchymosis, emphysema, hematoma, skin pierced, wound infection and skin burn. Overall incidence of hypoparathyroidism is $5.6-7.1 \%$, RLN injury is $3.1-4.3 \%$ and mental nerve palsy is $1.5-4.3 \%(13,14)$. Temporary and permanent RLN injury rates are similar to that of open thyroidectomy, which has been reported between the range $2.11 \%$ to $11.8 \%$ and $0.2 \%$ to $5.9 \%$, respectively $(15-17)$. Chan et al. indicated that the incidence of complications after TOETVA in their study is similar to that of open thyroidectomy (14).

Today, TOETVA is widely used technique as a novel treatment for surgical thyroid disease all over the world. The technique, including IONM is feasible and safe. The surgeon can identify and check the function of the RLN and external branch of the superior laryngeal nerve easily with the help of IONM. It is well known that IONM is mainly helpful in nerve identification and mapping, dissection, nerve damage detection and postoperative nerve prognosis estimation. In particular, IONM is a functional method that contributes to the detection of neuropraxia due to traction, heat or compression. Another benefit of IONM is the completion of dissection by intermittent nerve stimulation after the nerve is found. This method can be very useful, especially in nerves with branching. Although neuromonitoring has important implications for nerve identification and dissection, its main function is to predict postoperative laryngeal function in the intraoperative 


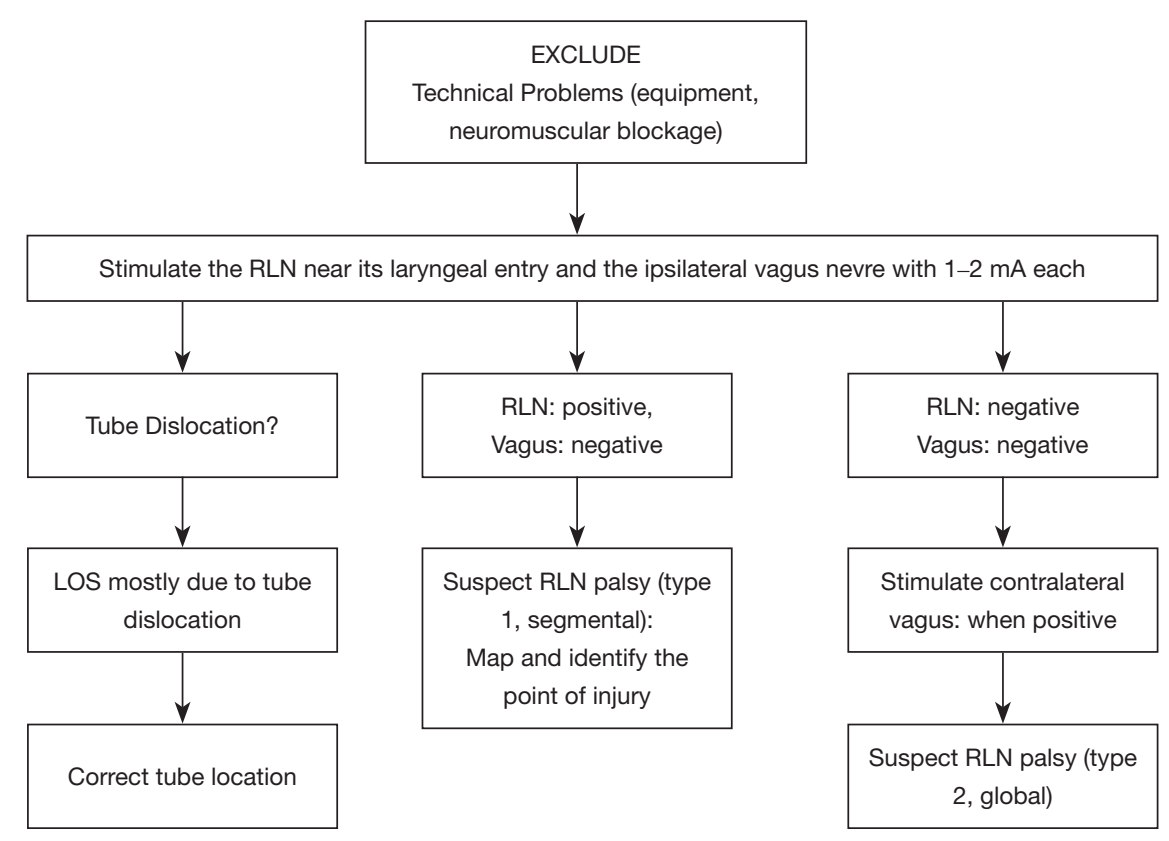

Figure 2 Troubleshooting algorithm after LOS during TOETVA. TOETVA, transoral endoscopic thyroidectomy by vestibular approach.

period. Structurally seeming healthy nerve does not mean that it is functional. Thus, RLN injury can be effectively avoided by perioperative nerve monitoring system $(18,19)$. During TOETVA, the surgeon can damage the RLN during thyroid gland retraction with a forcep. Besides, evaluation of the RLN function is extremely important for planned bilateral thyroidectomies (20). In fact, in the event of a significant reduction or loss of the neuromonitoring signal, it is strongly recommended not to dissect the contralateral side. In this case, a completion thyroidectomy will be made afterwards in a second surgical intervention, so-called 'staged-thyroidectomy' (21).

The foremost benefit of IONM administration is that it contributes to altering the operative strategy in unilateral damage. Consequently, visual assessment of RLN is insufficient to evaluate function in the postoperative period. As said in this regard, the most important instrument is seen as IONM. IONM in TOETVA requires training. It is unwise to use IONM for the first time with TOETVA, without any prior nerve monitoring experience. TOETVA can be performed safely in selected patients by an experienced surgeon and IONM is an adjunct of utmost safety importance.

\section{Acknowledgments}

None.

\section{Footnote}

Conflicts of Interest: The authors have no conflicts of interest to declare.

Ethical Statement: The authors are accountable for all aspects of the work in ensuring that questions related to the accuracy or integrity of any part of the work are appropriately investigated and resolved.

\section{References}

1. Song CM, Tae K. Robotic thyroidectomy: evolution and outcomes. Hanyang Med Rev 2016;36:205-10.

2. Witzel K, von Rahden BH, Kaminski C, et al. Transoral access for endoscopic thyroid resection. Surg Endosc 2008;22:1871-5.

3. Anuwong A, Ketwong K, Jitpratoom P, et al. Safety and outcomes of the transoral endoscopic thyroidectomy vestibular approach. JAMA Surg 2018;153:21-7.

4. Lamade W, Fogel W, Rieke K, et al. Intraoperative monitoring of the recurrent laryngeal nerve. A new method. Chirurg 1996;67:451-4.

5. Lamadé W, Meyding-Lamade U, Buchhold C, et al. First continuous nerve monitoring in thyroid gland surgery. Chirurg 2000;71:551-7.

6. Hermann M, Alk G, Roka R, et al. Laryngeal recurrent 
nerve injury in surgery for benign thyroid diseases: effect of nerve dissection and impact of individual surgeon in more than 27,000 nerves at risk. Ann Surg 2002;235:261-8.

7. Barczyński M, Randolph GW, Cernea CR, et al. External branch of the superior laryngeal nerve monitoring during thyroid and parathyroid surgery: International Neural Monitoring Study Group standards guideline statement. Laryngoscope 2013;123 Suppl 4:S1-14.

8. Randolph GW, Dralle H; International Intraoperative Monitoring Study Group, et al. Electrophysiologic recurrent laryngeal nerve monitoring during thyroid and parathyroid surgery: international standards guideline statement. Laryngoscope 2011;121 Suppl 1:S1-16.

9. Randolph G. Surgical anatomy of the recurrent laryngeal nerve. In: Randolph G. editor. (ed). Surgery of the thyroid and parathyroid glands. 1st edition. Philadelphia, Saunders, 2003;300:42.

10. Uludag $M$, Isgor A. Intraoperative nevre monitoring: Technical details. In: Isgor A, Uludag M. editors. Thyroid. First edition. Istanbul Nobel Medical Bookstores, 2013:917-32.

11. Celik S, Makay O, Yoruk MD, et al. A surgical and anatomo-histological study on Transoral Endoscopic Thyroidectomy Vestibular Approach (TOETVA). Surg Endosc 2020;34:1088-102.

12. Zhang D, Mazzeo C, Dionigi G, et al. Nerve Monitoring for Transoral Thyroid Surgery: Why, How, and What to Expect. Curr Otorhinolaryngol Rep 2019;7:225-31.

13. Shan L, Liu J. A Systemic Review of Transoral Thyroidectomy. Surg Laparosc Endosc Percutan Tech 2018;28:135-8.

Cite this article as: Erol V, Dionigi G, Barczyński M, Zhang D, Makay Ö. Intraoperative neuromonitoring of the RLNs during TOETVA procedures. Gland Surg 2020;9(Suppl 2):S129-S135. doi: $10.21037 /$ gs.2019.11.21
14. Chen S, Zhao M, Qiu J. Transoral vestibule approach for thyroid disease: a systematic review. Eur Arch Otorhinolaryngol 2019;276:297-304.

15. Song CM, Jung JH, Ji YB, et al. Relationship between hypoparathyroidism and the number of parathyroid glands preserved during thyroidectomy. World J Surg Oncol 2014;12:200.

16. Ywata de Carvalho A, Chulam TC, Kowalski LP. Longterm results of observation vs prophylactic selective level VI neck dissection for papillary thyroid carcinoma at a cancer center. JAMA Otolaryngol Head Neck Surg 2015;141:599-606.

17. Calò PG, Pisano G, Medas F, et al. Identification alone versus intraoperative neuromonitoring of the recurrent laryngeal nerve during thyroid surgery: experience of 2034 consecutive patients. J Otolaryngol Head Neck Surg 2014;43:16.

18. Inabnet WB 3rd, Suh H, Fernandez-Ranvier G. Transoral endoscopic thyroidectomy vestibular approach with intraoperative nerve monitoring. Surg Endosc 2017;31:3030.

19. Chen HK, Chen CL, Wen KS, et al. Application of transoral continuous intraoperative neuromonitoring in natural orifice transluminal endoscopic surgery for thyroid disease: a preliminary study. Surg Endosc 2018;32:517-25.

20. Dionigi G, Wu CW, Tufano RP, et al. Monitored transoral endoscopic thyroidectomy via long monopolar stimulation probe. J Vis Surg 2018;4:24.

21. Dionigi G, Lavazza M, Bacuzzi A, et al. Transoral endoscopic thyroidectomy vestibular approach (TOETVA): From A to Z. Surg Technol Int 2017;30:103-12. 